\title{
Exfoliation and dispersion of LDH modified with $N$-tetrabromophthaloyl-glutamic in poly(vinyl alcohol): Morphological and thermal studies
}

\author{
SHADPOUR MALLAKPOUR ${ }^{\mathrm{a}, \mathrm{b}, \mathrm{c}, *}$, MOHAMMAD DINARI $^{\mathrm{a}, \mathrm{b}}$ and MEYSAM TALEBI ${ }^{\mathrm{a}}$ \\ ${ }^{a}$ Organic Polymer Chemistry Research Laboratory, Department of Chemistry, Isfahan University \\ of Technology, Isfahan, 84156-83111, I. R. Iran \\ ${ }^{b}$ Nanotechnology and Advanced Materials Institute, Isfahan University of Technology, Isfahan, \\ 84156-83111, I. R. Iran \\ ${ }^{\mathrm{c}}$ Center of Excellence in Sensors and Green Chemistry, Department of Chemistry, Isfahan University \\ of Technology, Isfahan, 84156-83111, Islamic Republic of Iran \\ e-mail: mallak@cc.iut.ac.ir; mallak777@yahoo.com; mallakpour84@alumni.ufl.edu
}

MS received 4 August 2014; revised 15 September 2014; accepted 3 October 2014

\begin{abstract}
In this study, modified LDH (M-LDH) was synthesized by the co-precipitation reaction of $\mathrm{Al}\left(\mathrm{NO}_{3}\right)_{3} \cdot 9 \mathrm{H}_{2} \mathrm{O}, \mathrm{Mg}\left(\mathrm{NO}_{3}\right)_{2} \cdot 6 \mathrm{H}_{2} \mathrm{O}$ and $\mathrm{N}$-tetrabromophthaloyl-glutamic (Br-Gl) in short time. M-LDH nanofillers were embedded into poly(vinyl alcohol) (PVA) matrix via ultrasonic irradiation technique which provided PVA/M-LDH NCs. The morphology and structure of the prepared samples were characterized by Fourier transform infrared spectroscopy, thermogravimetric analysis (TGA), field emission scanning electron microscopy and X-ray diffraction techniques TGA of the PVA/M-LDH NCs showed that the thermal stability was improved. The enhancement of thermal properties was ascribed to the homogeneous and good dispersion of M-LDH sheets in the PVA matrix by hydrogen bonding between O-H groups of PVA and the M-LDH.
\end{abstract}

Keywords. Modified layered double hydroxides; nanocomposite; thermal stability; poly(vinyl alcohol).

\section{Introduction}

Polymer nanocomposites (NCs) are of scientific and industrial interest due to their superior properties arising from the nano-fillers. Various inorganic fillers, fibres and anisotropic particles such as layered silicates, ${ }^{1}$ carbon nanotubes ${ }^{2-4}$ and so on, have confirmed to be particularly useful in strengthening polymer matrix. Recently, another kind of inorganic nano-filler, layered double hydroxide (LDH), known as anionic clays, has attracted much attention. The hydroxide layers of $\mathrm{LDH}$ have close likeness to the mineral brucite, or $\operatorname{Mg}(\mathrm{OH})_{2}$, where some divalent cation in the brucite layers are replaced by a trivalent cation, generating positively charged layers. General formula for these compounds is $\left[\mathrm{M}^{2+}{ }_{1-\mathrm{x}} \mathrm{M}^{3+}{ }_{\mathrm{x}}(\mathrm{OH})_{2}\right]\left(\mathrm{A}^{\mathrm{m}-}\right)_{\mathrm{x} / \mathrm{m}} \cdot \mathrm{nH}_{2} \mathrm{O}$, in which both $\mathrm{M}^{2+}$ and $\mathrm{M}^{3+}$ can be varied, and $\mathrm{A}^{\mathrm{m}-}$ is usually an exchangeable anion. ${ }^{5}$ LDHs are considered as important layered crystals because of their biocompatibility, biodegradability and their practical applications in catalysis, ${ }^{6}$ flame retardants, ${ }^{7}$ photochemistry, ${ }^{8}$ abilities to intercalate, as antioxidant, ${ }^{9}$ adsorption-desorption of water

*For correspondence pollutant ions, ${ }^{10,11}$ biohybrid beads and in controlled release of medicine. ${ }^{12-14}$ The characteristic that makes LDH appropriate for these applications is the exchangeable nature of the interlayer anions. In the early development of hybrid inorganic-organic composites, modifications with surfactants were developed to convert clay surfaces from hydrophilic to organophilic and to increase the basal spacing of layers. ${ }^{15-17}$

Glutamic acid (Gl), a non-essential amino acid, has a wide variety of applications, for instance, as antioxidants, ${ }^{18}$ gene transfection, ${ }^{19}$ detection and identification of cationic and non-ionic surfactants. ${ }^{20}$

Poly(vinyl alcohol) (PVA) is a polyhydroxy water soluble polymer that has been studied largely due to its many attractive characteristics, such as, biodegradability, biocompatibility and water-solubility. PVA has been used for membranes, ${ }^{21}$ drug delivery systems, ${ }^{22}$ artificial biomedical devices, bioadhesive anti-bacterial system $^{23-26}$ and hybrid NC coatings. ${ }^{27}$ These applications have encouraged researchers to improve thermal, mechanical, super-ductility properties of PVA. ${ }^{28}$ More recently, PVA-based NCs have been developed to improve PVA properties by intercalating various surfactants in LDH nanoparticle. ${ }^{29,30}$ 
This work was focused on investigation of the properties of novel NCs fabricated from PVA and modified LDH (M-LDH). The dicarboxylate anion of $(N-$ tetrabromophthaloyl-glutamic) (Br-Gl) diacid was prepared from a reaction of tetrabromophtalic anhydride with Gl. Then Br-Gl diacid was intercalated in LDH to prepare M-LDH. Different amounts of M-LDH were used for the synthesis of PVA/M-LDH NCs under ultrasonic irradiation. The structure and morphology of the M-LDH and PVA/M-LDH NCs were characterized by Fourier transform infrared spectroscopy (FT-IR), X-ray diffraction (XRD), thermogravimetric analysis (TGA) and field emission scanning electron microscopy (FESEM). Due to the presence of different functional groups in the diacid molecule, it can be dispersed well in the PVA matrix which can also enhance the properties of the hybrid materials.

\section{Experimental}

\subsection{Apparatus}

The interlayer spacing of all samples were measured by XRD (Bruker, D8 Advance, Germany) with $\mathrm{Cu}$ $\mathrm{K} \alpha$ radiation $(\lambda=0.1542 \mathrm{~nm})$ at $45 \mathrm{kV}$ and $100 \mathrm{~mA}$. The diffraction patterns were collected at $2 \theta$ between $5-80^{\circ}$ at a scanning rate of $0.05^{\circ} / \mathrm{min}$. Basal spacing was determined from the position of the $d(003)$ reflection. The d-spacing of the samples was analyzed using Bragg's equation $(\mathrm{n} \lambda=2 \mathrm{~d} \sin \theta)$. Where $\mathrm{n}$ is an integer, $\lambda$ is the wavelength, $\theta$ is the glancing angle of incidence, and $\mathrm{d}$ is the interplanar spacing of the crystal. The reaction was carried out on a MISONIX ultrasonic liquid processor, XL-2000 SERIES. Ultrasound was at a frequency of $2.25 \times 10^{4} \mathrm{~Hz}$ and power, 100 W. A Jasco-680 FT-IR spectrometer (Japan) was employed $\mathrm{KBr}$ pellet technique was applied to monitor the FT-IR spectra of the samples in the range of $4000-400 \mathrm{~cm}^{-1}$. TGA was performed on an STA503 TA instrument in a nitrogen atmosphere at the heating rate of $20^{\circ} \mathrm{C} / \mathrm{min}$ from ambient temperature to $800^{\circ} \mathrm{C}$. The morphology of M-LDH and NCs was examined by FE-SEM (ZEISS; $\left.\sum I G M A-V T\right)$.

\subsection{Materials}

PVA (99\% hydrolysis, weight-average molecular weight $=72,000 \mathrm{~g} / \mathrm{mol}$ ), tetrabromophthtalic anhydride (4,5,6,7-tetrabromoisobenzofuran-1,3-dion), Gl, and sodium hydroxide $(\mathrm{NaOH})$ were purchased from Merck Chemical Co. Aluminum nitrate $\mathrm{Al}\left(\mathrm{NO}_{3}\right)_{3} \cdot 9 \mathrm{H}_{2} \mathrm{O}$ and magnesium nitrate $\mathrm{Mg}\left(\mathrm{NO}_{3}\right)_{2} \cdot 6 \mathrm{H}_{2} \mathrm{O}$ were purchased from Aldrich Chemical Co. Other solvents and materials were used as obtained without further purification.

\subsection{Preparation of $\mathrm{Br}$-Gl diacid}

The Br-Gl diacid was synthesized according to the general procedure: ${ }^{31} 2 \mathrm{mmol}$ of the tetrabromophtalic anhydride was mixed with $4 \mathrm{mmol}$ of the $\mathrm{Gl}$ in $10 \mathrm{~mL}$ of acetic acid, and the mixture was stirred at room temperature for $12 \mathrm{~h}$ and then refluxed for $24 \mathrm{~h}$. Then the acetic acid was distilled under vacuum and the residue poured into $1 \%$ of $\mathrm{HCl}$ solution. The solid was filtered, washed with $1 \% \mathrm{HCl}$ solution and several times with water and then dried in vacuum.

\subsection{Preparation of the modified $\mathrm{LDH}$}

M-LDH was prepared by an ultrasound-assisted coprecipitation method. A solution of diacid $\mathrm{Br}-\mathrm{Gl}$ was prepared by dissolving $\mathrm{NaOH}(0.02 \mathrm{~mol})$ and diacid $(0.02 \mathrm{~mol})$ in $20 \mathrm{~mL}$ of deionized water. Then aqueous solution of $\mathrm{Al}\left(\mathrm{NO}_{3}\right)_{3} \cdot 9 \mathrm{H}_{2} \mathrm{O}$ and $\mathrm{Mg}\left(\mathrm{NO}_{3}\right)_{2} \cdot 6 \mathrm{H}_{2} \mathrm{O}$ $(\mathrm{Mg} / \mathrm{Al}$ molar ratio of 2:1) were added dropwise to this solution and the mixture was vigorously stirred at $\mathrm{pH}=10$ for $20 \mathrm{~min}$ at room temperature. The product was sonicated for $1 \mathrm{~h}$ and then filtered and washed several times with water, and then dried in vacuum to give the M-LDH nanolayers.

\subsection{Preparation of the PVA/M-LDH NC films}

PVA/M-LDH NCs were synthesized by a solution casting method. At first, PVA was dissolved in water under stirring at $70^{\circ} \mathrm{C}$, and $\mathrm{M}-\mathrm{LDH}$ was dispersed in water at $60^{\circ} \mathrm{C}$ to form a suspension. Then PVA was added to the suspensions of M-LDH and stirred at $60^{\circ} \mathrm{C}$ for $2 \mathrm{~h}$. For uniform dispersing of M-LDH in PVA, this aqueous mixture was sonicated for $1 \mathrm{~h}$ and poured into Petri dish in a closed oven at $40^{\circ} \mathrm{C}$ for approximately $24 \mathrm{~h}$ to evaporate water. The M-LDH contents in the PVA NC films were 2, 4 and $8 \mathrm{wt} \%$.

\section{Results and Discussion}

\subsection{Synthesis of M-LDH and PVA/M-LDH NCs}

By the condensation reaction of an equimolar amount of tetrabromophtalic anhydride and two equimolar amounts of the Gl in reflux acetic acid corresponding $\mathrm{Br}-\mathrm{Gl}$ diacid was synthesized, as shown in scheme 1. Then the solution of this compound was added to the solution of aluminum nitrate and magnesium 
<smiles>CC(C)C(=O)N1C(=O)c2c(Br)c(Br)c(Br)c(Br)c2C(=O)[C@]1(CCC(=O)O)C(=O)O</smiles>

Scheme 1. Preparation of Br-Gl diacid.

nitrate, under ultrasonic irradiation to prepare M-LDH (figure 1).

Novel PVA/M-LDH NCs with 2, 4 and $8 \mathrm{wt} \%$ of MLDH were successfully fabricated by solution casting method. Different amounts of M-LDH were mixed with the PVA and the mixture was dispersed in water, under ultrasonic irradiation to prepare PVA/M-LDH NCs (figure 2). The uniform distribution of M-LDH in the polymer matrix was expected to lead to enhancement of physical, morphological and thermal properties in the resulting NCs.

\subsection{FT-IR study}

PVA, LDH, M-LDH and PVA/M-LDH NCs containing 2, 4 and $8 \mathrm{wt} \%$ of M-LDH sheets were characterized by FT-IR spectroscopy. For $\mathrm{LDH}-\mathrm{CO}_{3}^{2-}$, the broad peak centred at about $3400 \mathrm{~cm}^{-1}$ arised from O-H stretching vibration of the metal hydroxide layer and interlayer water molecules. The strong peaks at 1373 and $1045 \mathrm{~cm}^{-1}$ were attributed to the stretching vibration of $\mathrm{CO}_{3}^{2-}$. In the FT-IR spectrum of the Br-Gl, bands at $1770-1717 \mathrm{~cm}^{-1}$ were attributed to $\mathrm{C}=\mathrm{O}$ stretching vibration. Bands in $1300-1000 \mathrm{~cm}^{-1}$ range are assigned to the $\mathrm{C}-\mathrm{O}$ stretching and in $1600-1475 \mathrm{~cm}^{-1}$ range, assigned to $\mathrm{C}=\mathrm{C}$ stretching vibration of $\mathrm{Br}-\mathrm{Gl}$ (figure $3 \mathrm{~b}$ ). Band broadening resulted due to intercalation and electrostatic interaction between chiral diacid molecules (figure 3c). In the case of PVA, a broad absorption peak centred at around $3350 \mathrm{~cm}^{-1}$ is ascribed to $\mathrm{O}-\mathrm{H}$ stretching vibration of hydrogen bond of hydroxyl groups. The absorption peak around $2938 \mathrm{~cm}^{-1}$ is related to stretching vibrations of $-\mathrm{CH}$

\section{$\mathrm{Al}\left(\mathrm{NO}_{3}\right)_{3} \cdot 6 \mathrm{H}_{2} \mathrm{O}$

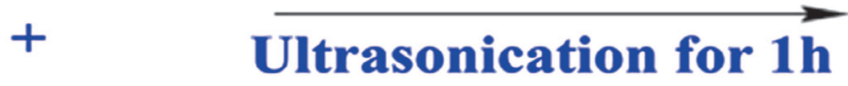

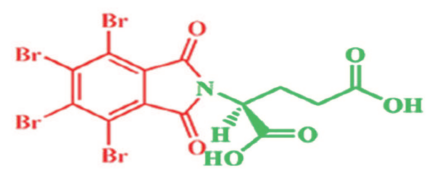

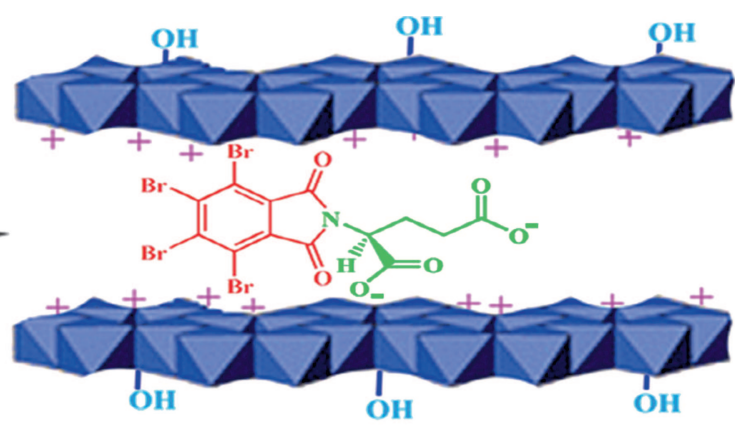

M-LDH

Figure 1. Preparation of the M-LDH.

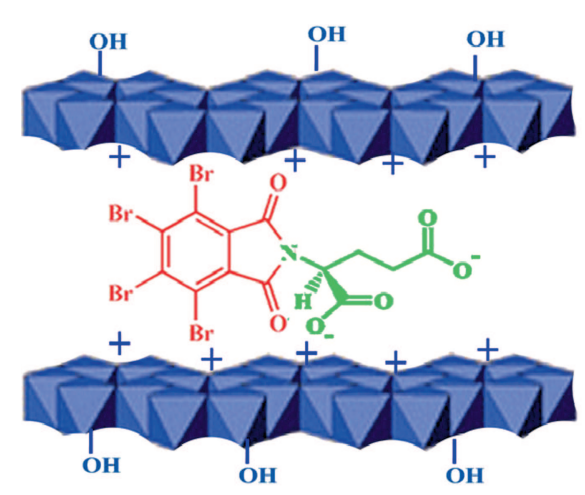

M-LDH
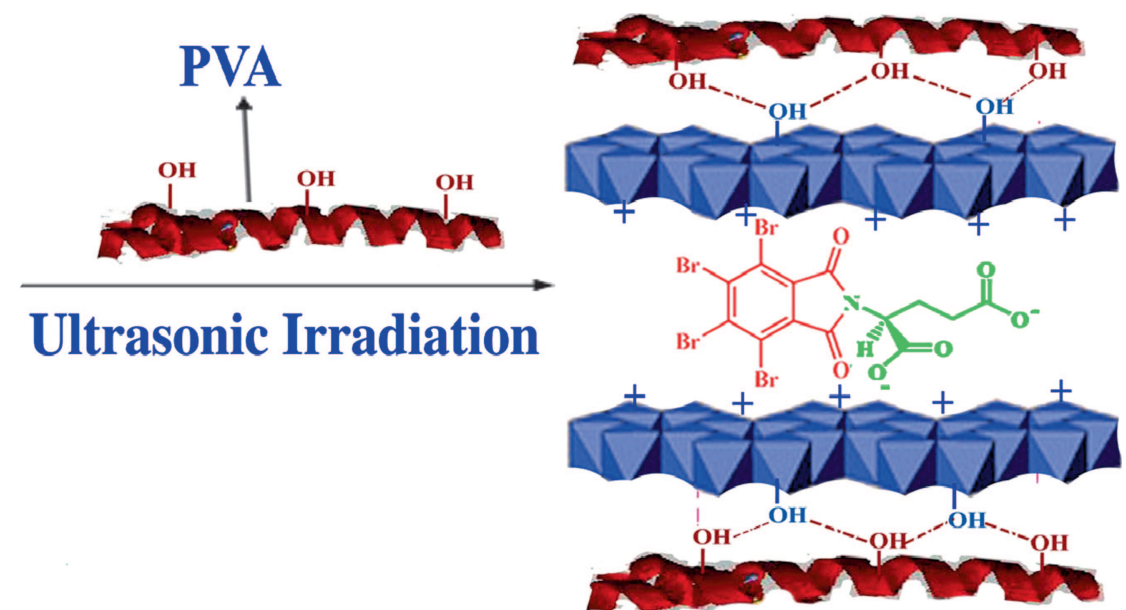

PVA/M-LDH NC

Figure 2. Preparation of the PVA/M-LDH NCs. 


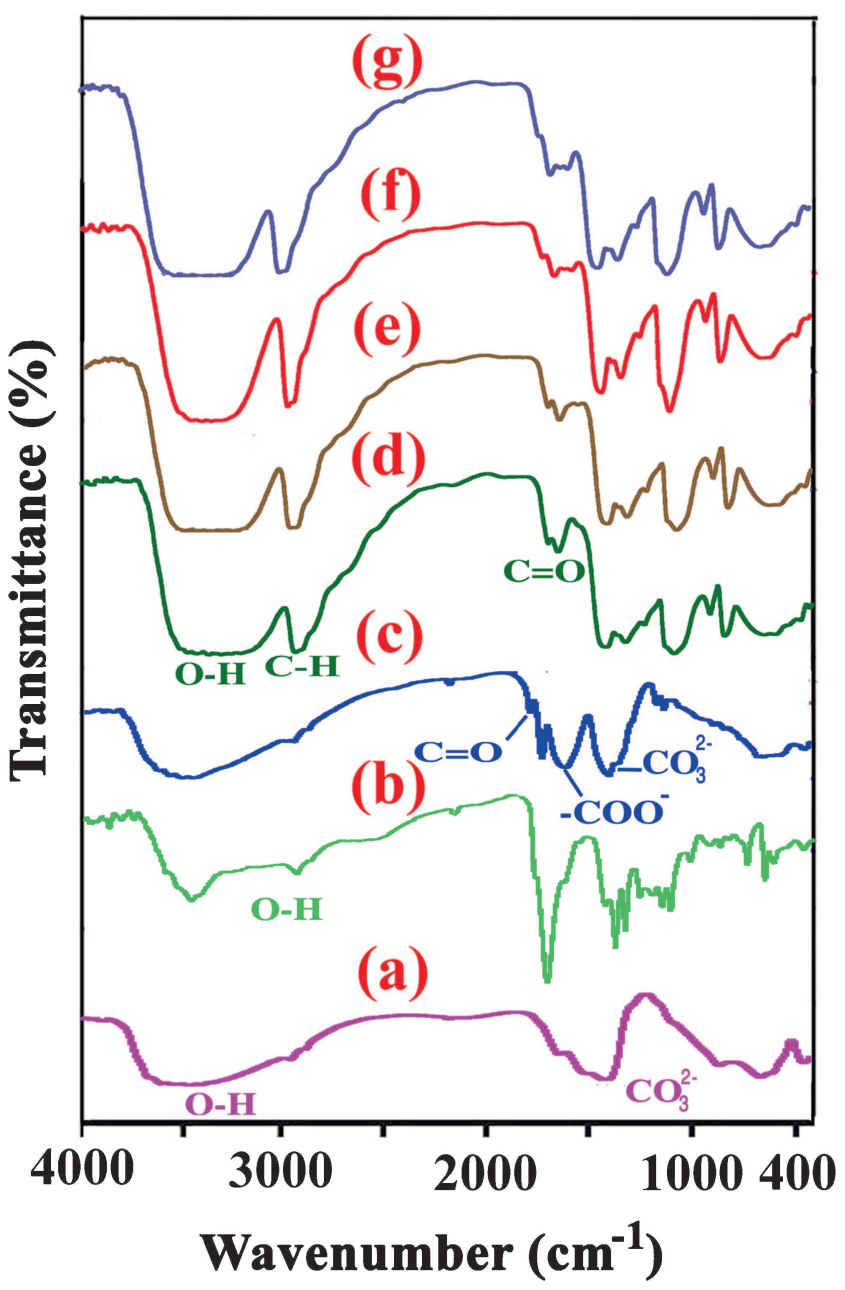

Figure 3. (a) FT-IR spectra of LDH; (b) $\mathrm{Br}-\mathrm{Gl}$; (c) $\mathrm{M}$ LDH; (d) PVA; and (e-g) different PVA/M-LDH NCs of M-LDH.

and $\mathrm{CH}_{2}$ groups. Strong absorption peak observed at $1708 \mathrm{~cm}^{-1}$ is characteristic of the carbonyl group of the acetate in the partially hydrolyzed PVA. The peaks at 1428 and $1330 \mathrm{~cm}^{-1}$ are characteristic of the $\mathrm{O}-\mathrm{H}$ and C-H deformation vibration, respectively. The absorption peak at $1000-1100 \mathrm{~cm}^{-1}$ could be assigned to the $\mathrm{C}-\mathrm{O}$ stretching and $\mathrm{O}-\mathrm{H}$ bending vibrations arising from the PVA chain (figure 3d). It could be easily seen that for PVA/M-LDH NCs 2, 4 and $8 \mathrm{wt} \%$, the NCs have characteristic band of neat PVA with a little shift to the left (figure $3 \mathrm{e}-\mathrm{g}$ ).

\section{$3.3 X$-ray diffraction}

One of the complementary techniques to characterize the extent of intercalation and delamination of the nano-filler having layered structure is XRD. The XRD spectra of pristine LDH, M-LDH, PVA and PVA/MLDH NCs with 4 and $8 \mathrm{wt} \%$ of MLDH are shown in figure 4. Before organic treatment, the basal spacing of

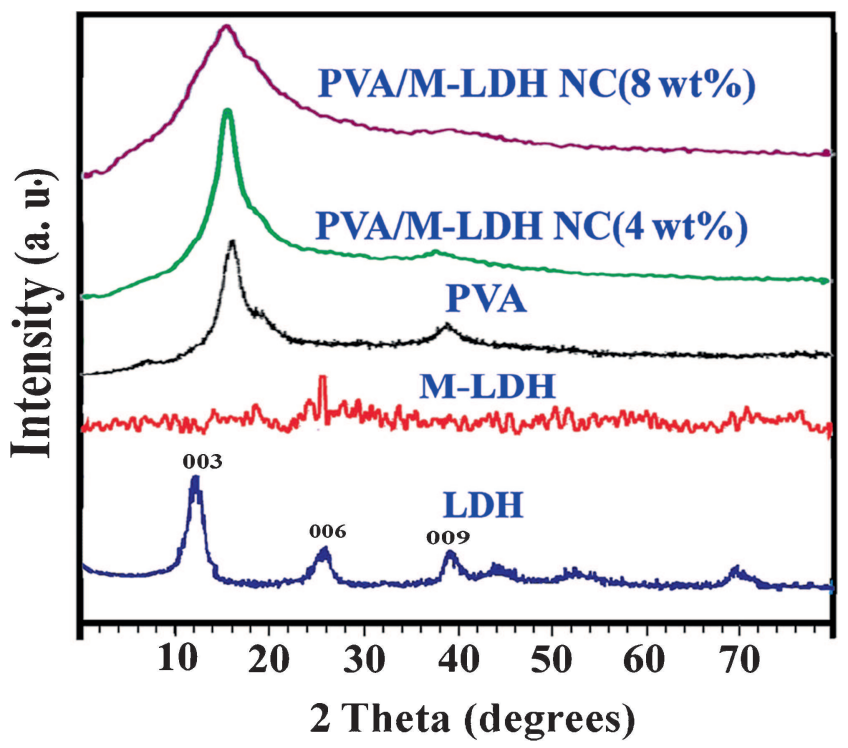

Figure 4. XRD patterns of LDH, M-LDH, PVA, PVA/MLDHNCs with 4 and 8 wt $\%$ of M-LDH.

the pure LDH was $0.75 \mathrm{~nm}$, which corresponds to the (003) diffraction peak with $2 \theta=11.84^{\circ}$. The XRD pattern of pristine LDH showed that this compound is highly crystalline in nature. After treatment with chiral dicarboxylic acid Br-Gl, the XRD pattern of M-LDH showed absence of (003) diffraction peak as a result of the exfoliation. As shown in figure 4, PVA has a low degree of semi-crystalline structure due to numerous hydrogen bonds of the hydroxyl groups. The XRD patterns of PVA/MLDH NCs showed similar XRD patterns to the PVA when the M-LDH composition was $4 \%$ and $8 \mathrm{wt} \%$.

\subsection{Thermal degradation characteristic}

Comparison of TGA of the M-LDH with LDH gives an indication of how the interlayer surfactant anions manipulate the decomposition of the host material. As shown in figure 5, TGA of LDH and M-LDH suggests a two-stage decomposition process: the first weight loss stage is related to the loss of absorbed water molecules and the second weight loss stage between 370 and $500^{\circ} \mathrm{C}$ could be assigned to the removal of interlayer carbonate and dehydroxylation of the metal hydroxide layer. $^{32}$

As shown in figure 6, a three step degradation can be observed for PVA. The first step of weight loss is related to the loss of absorbed water. The second weight loss is associated with the degradation of the PVA by dehydration reaction of the polymer chain. The third step of weight loss is related to the cleavage backbone of PVA polymer. In case of PVA/M-LDH NCs, an increase in thermal stability between $250-470^{\circ} \mathrm{C}$ for 


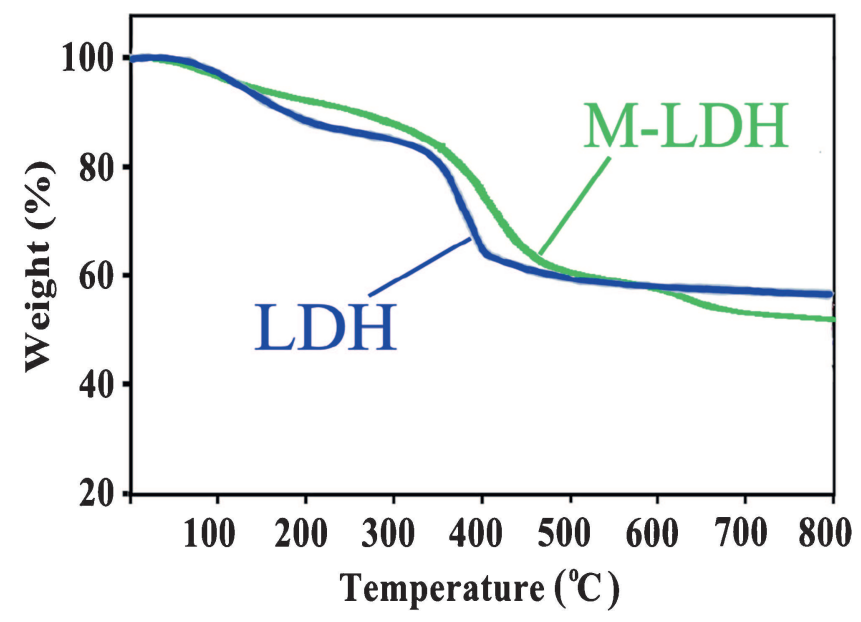

Figure 5. TGA curves of pure LDH and M-LDH.

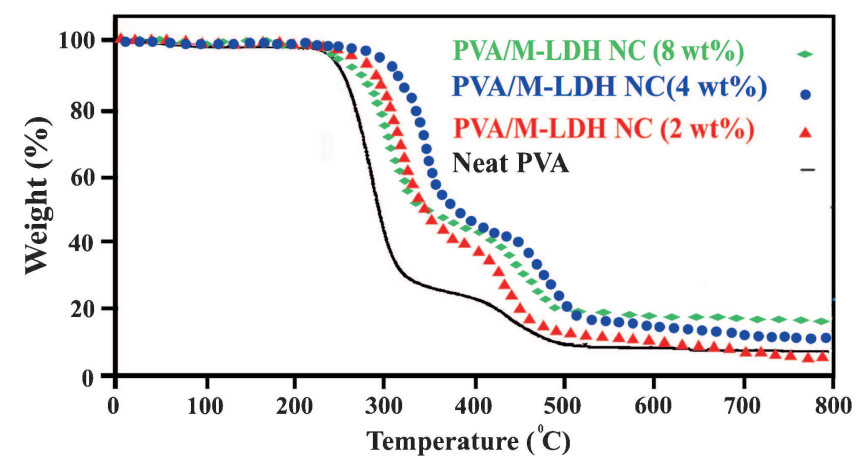

Figure 6. TGA curves of PVA and PVA/M-LDH NCs with 2,4 and 8 wt $\%$ of M-LDH.

the NCs was observed. The increase in thermal stability was pointed out by an increase of about $70^{\circ} \mathrm{C}$ in the onset of the thermal decomposition temperature. This was similar to result obtained for other LDH-based NCs. ${ }^{33}$ The NC films showed more resistance toward thermal degradation. The residue at $800^{\circ} \mathrm{C}$ (char yield) for NCs with 2, 4 and $8 \mathrm{wt} \%$ of M-LDH were 5\%,10\% and $20 \%$, respectively. Char yield for NCs 4 and $8 \mathrm{wt} \%$ of M-LDH was significantly increased (figure 6). The improvement of thermal properties maybe attributed to the homogeneous and well-dispersed M-LDH sheets in the PVA matrix and strong hydrogen bonding between $\mathrm{O}-\mathrm{H}$ groups of PVA and the layers of M-LDH sheets. ${ }^{34}$ The char yield of hybrid PVA/M-LDH NCs is obviously elevated in comparison to PVA, displaying that the thermal stability of the hybrid NCs is enhanced by the incorporation of M-LDH nanolayers.

\subsection{FE-SEM and TEM studies}

To study the changes in the morphology of LDH, MLDH, PVA and PVA/M-LDH NCs, FE-SEM imaging of the samples was carried out. The morphological images
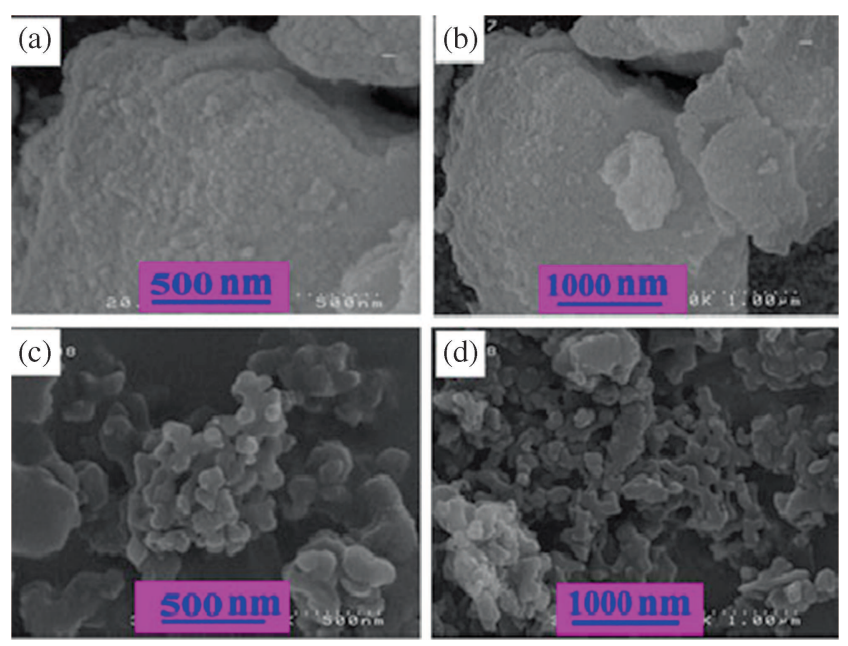

Figure 7. (a, b) FE-SEM images of LDH and; (c, d) MLDH.

of $\mathrm{LDH}$ and $\mathrm{M}-\mathrm{LDH}$ were investigated by FE-SEM as shown in figure 7. The unmodified LDH showed rough plate-like shapes loaded on top of each other (figures $7 \mathrm{a}, \mathrm{b}$ ). In the case of M-LDH, FE-SEM results demonstrated that the M-LDH layers lost their ordered stacking structure and were exfoliated (figure $7 \mathrm{c}, \mathrm{d}$ ). To further confirm the nanostructure of M-LDH and verify the conclusions from XRD and FE-SEM, TEM was carried out. Figure 8 shows the TEM of M-LDH. As shown in TEM photograph of M-LDH (figure $8 \mathrm{a}, \mathrm{b}$ ), dark colour indicated better ordered intercalated structure, and light gray showed uniform ultrathin sheets that was exfoliated. ${ }^{35}$

The FE-SEM micrographs of PVA and PVA/MLDH NCs with different M-LDH content are shown in figure 9. According to the results, the morphology of neat PVA was completely changed (figure $9 \mathrm{a}, \mathrm{b}$ ). The micrographs of the PVA hybrids with $2 \mathrm{wt} \%$ (figure 9c, d), $4 \mathrm{wt} \%$ (figure 9e, f) and $8 \mathrm{wt} \% \mathrm{M}-\mathrm{LDH}$ (figure $9 \mathrm{~g}$, h) showed that M-LDH nanosheets were well-dispersed in the polymer matrix, because M-LDH nano-filler had outstanding adhesion and strong interfacial bonding with PVA. It is observed that M-LDH nanosheets were homogeneously dispersed in the polymer matrix.
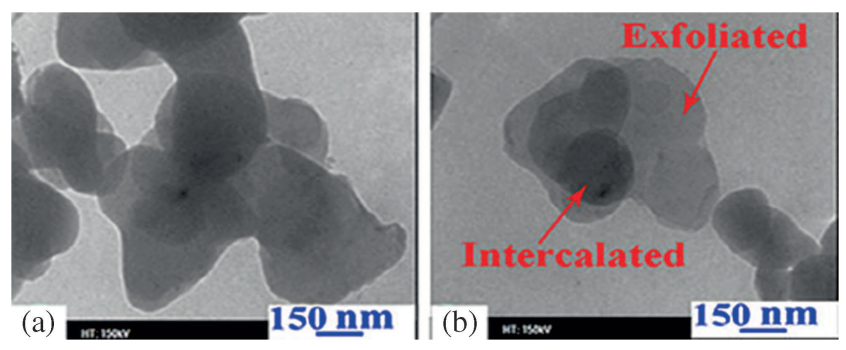

Figure 8. (a, b) TEM images of M-LDH. 

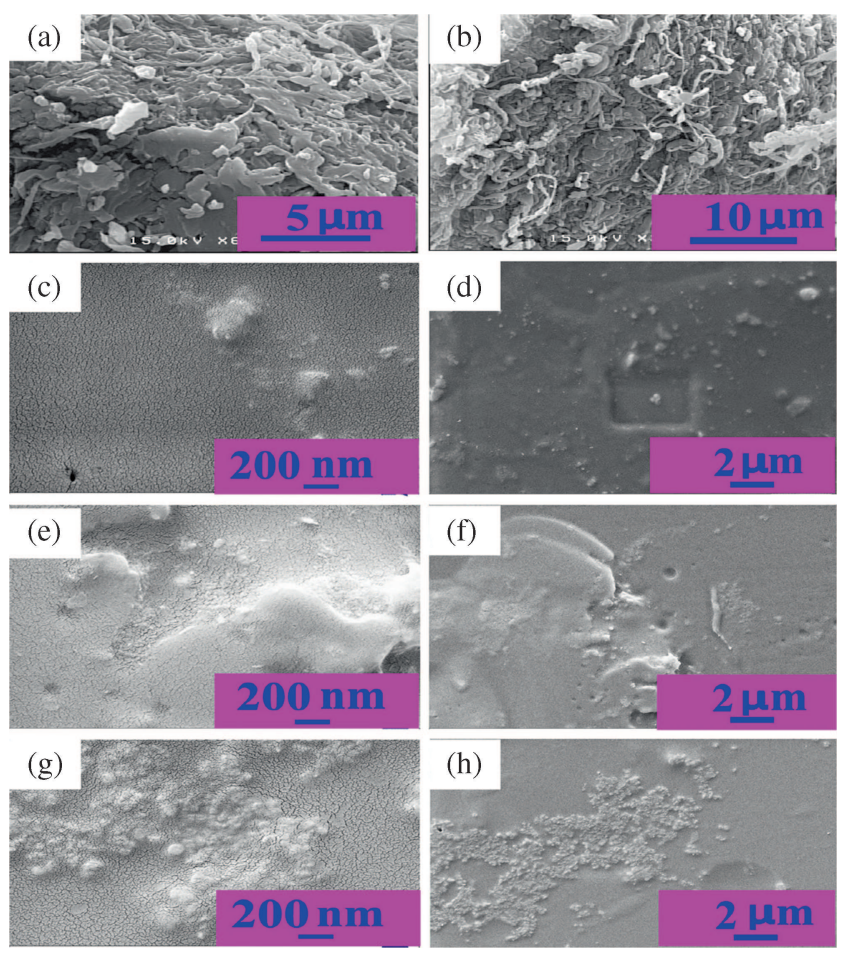

Figure 9. (a, b) FE-SEM images of PVA; (c, d);PVA/MLDH NCs $2 \mathrm{wt} \%$; (e, f) PVA/M-LDH NCs $4 \mathrm{wt} \%$; and $(\mathbf{g}, \mathbf{h})$ PVA/M-LDH NCs 8 wt $\%$.

\section{Conclusions}

In an efficient, simple and low cost strategy involving the use of ultrasonic irradiation technique, nanostructure $\mathrm{M}-\mathrm{LDH}$ intercalated with $\mathrm{Br}-\mathrm{Gl}$ was prepared to improve the thermal stability of PVA matrix. Then, NCs of PVA were prepared by a solution-intercalation method using the ultrasound energy, with different compositions (2, 4 and $8 \mathrm{wt} \%)$ of M-LDH. Dispersion of M-LDH was studied in FE-SEM micrographs. According to FE-SEM results, the morphology of the neat PVA was totally changed and the inorganic nanoparticles were dispersed homogenously in the PVA matrix. TGA indicated that thermal stability of the NCs was improved. Due to the homogeneous dispersion of $\mathrm{M}$ LDH nanosheets in the PVA matrix and strong hydrogen bonding between $\mathrm{O}-\mathrm{H}$ groups of PVA and the layers of $\mathrm{M}-\mathrm{LDH}$, an increase in thermal stability by about $70^{\circ} \mathrm{C}$ in the onset of the thermal decomposition was observed. Existence of amino acids in novel organo-modified nanoclay and PVA makes synthesized NCs suitable for industrial application such as fibres, textiles, packaging and so on.

\section{Acknowledgements}

We are grateful to the Research Affairs Division of Isfahan University of Technology (IUT), National Elite
Foundation (NEF), and Center of Excellence in Sensors and Green Chemistry Research (IUT).

\section{References}

1. Bahramian A R and Kokabi M 2009 J. Hazard. Mater. 166445

2. Ma P C and Zhang Y 2014 Renew. Sust. Energ. Rev. 30 651

3. Petrov P D and Georgiev G L 2012 Eur. Polym. J. 48 1366

4. Yang X, Zhang Z, Li J, Chen X, Zhang M, Luo L and Yao S 2014 Food Chem. 145687

5. Becker C M, Gabbardo A D, Wypych F and Amico S C 2011 Composites: Part A 42196

6. Parida K M Sahoo M and Singha S 2010 J. Mol. Catal. A: Chem. 3297

7. Xu S, Zhang L, Lin Y, Li R and Zhang 2012 J. Phys. Chem. Solids $\mathbf{7 3} 1514$

8. Seftel E M, Puscasu M C, Mertens M, Cool P and Carja G 2014 Appl. Catal. B: Environ. 150- 151157

9. Kong X, Jin L, Wei M and Duan X 2010 Appl. Clay Sci. 49324

10. Halajnia A, Oustan S, Najafi N, Khataee A R and Lakzian A 2013 Appl. Clay Sci. 80305

11. Liang X, Zang Y, Xu Y, Tan X, Houe W, Wang L and Sun Y 2013 Colloid. Surface A 433122

12. Ribeiro L N, Alcantara A C, Darder M, Arandaa P, Araujo-Moreir F M and Ruiz-Hitzky E 2014 Int. J. Pharm. 4631

13. Wang J, Liu Q, Zhang G, Li Z, Yang P, Jing X, Zhang M, Liu T and Jiang Z 2009 Solid-State Sci. 111597

14. Xia S J, Ni Z M, Xu Q, Hu B X and Hu J 2008 J. Solid State Chem. 1812610

15. Mallakpour S and Dinari M 2012 J. Polym. Environ. 20 732

16. Ouellet-Plamondon C M, Stasiak J and Al-Tabbaa A 2014 Colloid Surface A $\mathbf{4 4 4} 330$

17. Mallakpour S, Dinari M and Hatami M 2014 RSC Adv. 442114

18. Liu D Z, Lin Y S and Hou W C 2004 J. Agric. Food Chem. 522386

19. Liao Z X, Peng S F, Chiu Y L, Hsiao C W, Liu H Y, Lim W H, Lu H M and Sung H W 2014 J. Control. Release

20. Mohammad A and Shahab H 2006 Acta Chromatogr. 17 272

21. Zugic D L, Perovic I M, Nikolic V M, Maslovara S L and Marceta Kaninski M P M 2013 Int. J. Electrochem. Sci. 8949

22. Galeska I, Kim T-K, Patil S D, Bhardwaj U, Chatttopadhyay D, Papadimitrakopoulos F and Burgess D J 2005 Aaps. J. 7(1) 231

23. Wang X L, Oh I K and Lee S 2010 Sens. Actuators B 15057

24. Gonzalez J S, Maiolo A S, Hoppe C E and Alvarez V A 2012 Procedia Mater. Sci. 1483

25. Verma N and Chattopadhyay P 2012 Asian J. Pharm. Clin. Res. 50974

26. Yadav R and Kandasubramanian B 2013 Mater. Lett. 110130 
27. Rahimi M, Kameli P, Ranjbar M and Salamati H 2013 J. Magn. Magn. Mater. 347139

28. Zhang J, Wang J, Lin T, Wang C H, Ghorbani G, Fang J and Wang X 2014 Chem. Eng. J. 237 462

29. Mallakpour S and Dinari M 2014 Prog. Org. Coat. 77 583

30. Marangoni R, Mikowski A and Wypych F $2010 \mathrm{~J}$. Colloid Interface Sci. 351384
31. Tagle L H, Terraza C A, Tundidor-Camba A and Soto-Salamanca J 2014 Polym. Bull. 71287

32. Huang S, Cen X, Zhu H, Yang Z Yang Y, Tjiu W W and Liu T 2011 Mater. Chem. Phys. 130890

33. Zhao C X, Liu Y, Wang D Y, Wang D L and Wang Y Z 2008 Polym. Degrad. Stab. 931323

34. Bikiaris D 2011 Thermochim Acta $\mathbf{5 2 3} 25$

35. Ning W, Xingxiang Z, Na H and Shihe B 2009 Carbohydrate Polym. 7668 